\title{
Research on the Law of the Irrigation Water Infiltration in YaoBa Oasis Based on Hydrus-1D Model
}

\author{
Zheng Ce, Lu Yu-dong, Li Huan-huan \\ School of Environmental Science and Engineering, Chang'an University, Xi'an, China \\ Email address: \\ 459922848@qq.com (Zheng Ce), Luyudongphd@163.com (Lu Yu-dong), 17742499497@163.com (Li Huan-huan)
}

\section{To cite this article:}

Zheng Ce, Lu Yu-dong, Li Huan-huan. Research on the Law of the Irrigation Water Infiltration in YaoBa Oasis Based on Hydrus-1D Model. Earth Sciences. Vol. 4, No. 5, 2015, pp. 218-222. doi: 10.11648/j.earth.20150405.19

\begin{abstract}
To study the law of irrigation water infiltration in soil is the basis of putting forward reasonable irrigation system. This paper takes YaoBa Oasis in Alxa Zuoqi,Inner Mongolia, China as the research object, based on field investigations and data collection, and chooses three test sites at the field to obtain the parameters of the model. The change of soil water content in different depth was simulated by Hydrus-1D model in 30 days after irrigation. The results shows that under the local existing irrigation system, the groundwater recharge is limited, and loam is an ideal agricultural soil. The results of the simulation are in good agreement with the experimental results, so the research results can provide scientific basis for the development of a more reasonable irrigation scheme in YaoBa Oasis.
\end{abstract}

Keywords: YaoBa Oasis, Hydrus-1D Model, Irrigation Water, Infiltration Law

\section{基于Hydrus-1D模型的腰坝绿洲灌溉入渗规律研究}

\author{
郑策, 卢玉东, 李环环
}

环境科学与工程学院, 长安大学, 西安, 陕西, 中国

邮箱

459922848@qq.com(郑策), luyudongphd@163.com(卢玉东), 17742499497@163.com(李环环)

\begin{abstract}
摘要: 研究灌溉水在土壤中的入渗规律, 是提出合理灌溉制度的基础。本文以中国内蒙古阿拉善盟左旗腰坝绿洲为研 究对象, 在查阅文献、收集资料的基础上, 在当地选取三个试验点进行野外试验, 得到模型需要的参数。借助Hydrus $-1 \mathrm{D}$ 模型模拟灌溉后30天里不同深度土壤含水量变化情况, 分析其灌溉入渗规律。结果表明: 在当地现行的灌溉制度下灌 溉水对地下水的补给有限, 且壤土是比较理想的农业土壤。本次模拟所得结果与实际渗水试验结果较为吻合, 研究成 果可为腰坝绿洲制定更加合理的灌溉方案提供科学依据。
\end{abstract}

关键词: 腰坝绿洲, Hydrus-1D模型, 灌溉水, 入渗规律

\section{1. 引言}

灌溉作为农业领域最重要的水事活动, 对调节土壤的 水盐含量、保障作物的正常生长都有着极其重要的作用。 尤其对于干旱灌区而言, 土壤含水率是影响农作物生长的 关键因素, 并随着入渗过程而发生变化。入渗 [1] 是指水 分从土壤表面进入土壤内部形成土壤水的过程, 土壤水是
联系地表水与地下水的纽带, 灌溉水只有转化为土壤水才 能被植物吸收。入渗过程是在非饱和条件下土壤水的运移 过程, 属于广义渗流理论 [2]的研究范畴, 其理论基础是 由法国工程师Darcy提出的达西定律。由于野外试验受到 外部条件的限制, 随着计算机技术的快速应用与发展, 在 研究水分入渗过程时往往采取数值模拟的方法, 目前常用 的模型主要有SWAT、SWAP、WAVE以及Hydrus模型等。 
Hydrus-1D模型是由美国国家盐渍土改良中心 (US Salinity Laboratory) 在WORM、SWMI等模型基础上创建发 展而来的, 用于计算及模拟饱和一非饱和条件下的水分运 动和溶质运移的软件。软件自身携带有多种数学模型, 可 以灵活处理各种水流边界条件, 能够较好地模拟水分、溶 质与能量等在土壤中的分布及时空运移规律。尤其在分析 人们普遍较为关注的农田灌溉、田间施肥、环境污染等实 际问题上应用广泛。

随着中国科学技术的发展, Hydrus-1D模型也被越来 越多的中国学者用于不同灌区中土壤水分、盐分等的补给、 运移研究之中, 并取得了不错的成果。市建民等 [3] 利用 该模型对大安灌区旱田灌溉入渗补给进行了研究; 余根尖 等 [4]运用该模型模拟并分析了河套灌区不同灌水模式下 水分、盐分的运移规律; 马欢等 [5]依据该模型对位山灌 区的田间水循环规律进行了研究; 王水献等 [6]通过该模 型评价了焉老盆地试验区的土壤水资源量等。这些研究取 得的成果为不同地区灌溉制度的进一步发展提供了科学 依据。但是迄今为止, 还未曾有学者利用该模型对腰坝绿 洲进行过研究。

\section{2. 试验区概况及试验方法}

\section{1. 试验区概况}

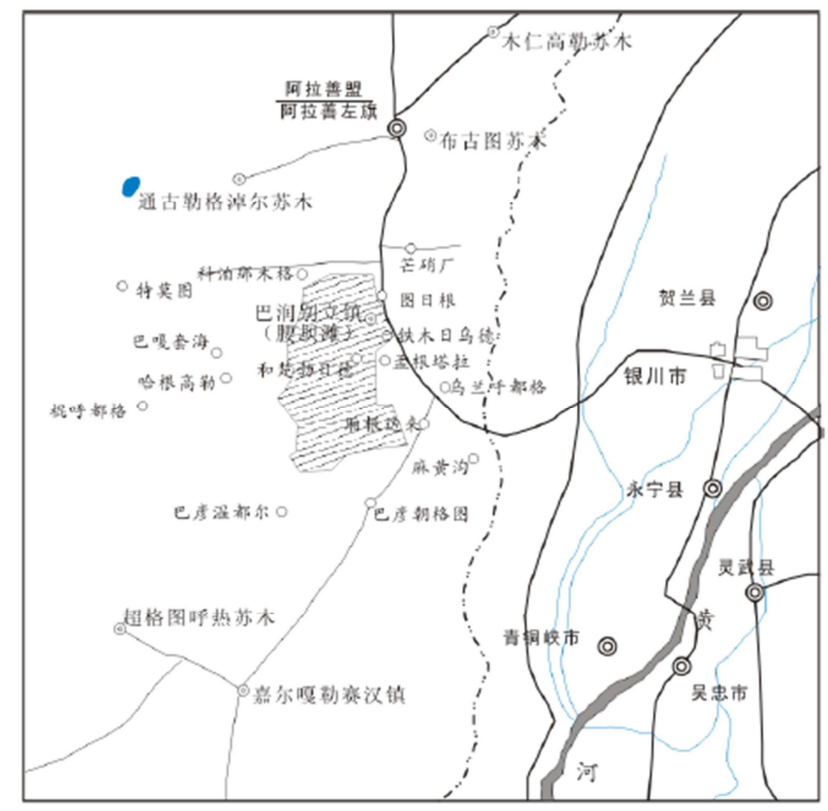

图1 腰坝绿洲地理位置示意图。

腰坝绿洲 [7]东临贺兰山, 西邻腾格里沙漠, 是中国 内蒙古阿拉善高原主要农牧区之一, 行政区划隶属中国内 蒙古自治区阿拉善左旗巴润别立镇, 面积约 30 万 $\mathrm{km}^{2}$, 地 势总体呈东高西低, 海拔为1290-1342米, 地理位置如图1 所示。试验区内的气候属于典型的大陆性干旱气候, 夏季 酷热而冬季寒冷, 全年降雨稀少, 气候干旱。腰坝绿洲位 于贺兰山西麓山前倾斜洪积平原水文地质区 [8], 赋存有 多层结构的孔隙水及承压水, 地下潜水位的埋深由东向西
逐渐变浅, 最浅处不足十米。由于本区内无地表径流, 地 下水的补给来源主要为侧向地下径流补给。

由于当地降水稀少, 也没有地表径流补给, 所以农业 所需要的水资源全部来源于地下水 $[9]$ 。连年的过度开采, 导致当地地下水位不断下降。同时地下水位的下降又引发 一系列的水质问题。因此合理利用水资源, 尤其是灌溉水, 对腰坝绿洲有着深远的影响。利用Hydrus $-1 \mathrm{D}$ 模型模拟腰 坝绿洲的灌溉入渗规律, 可为当地制定更加合理的灌溉制 度, 因此有着重要的意义。

\section{2. 试验方法}

由于试验区内的地下潜水位由东向西不断变浅, 故在 试验区东部、中部、西部各选择一处试验点进行试验, 坐 标分别为 1 号点 $\left(38^{\circ} 31^{\prime} 24.2^{\prime \prime} \mathrm{N}, 105^{\circ} 36^{\prime} 10.15^{\prime \prime} \mathrm{E}\right)$ 、 2 号点 $\left(38^{\circ} 30^{\prime} 5.95^{\prime \prime} \mathrm{N}, 105^{\circ} 34^{\prime} 34.94^{\prime \prime} \mathrm{E}\right) 、 3$ 号点 $\left(38^{\circ}\right.$ $\left.27^{\prime} 22.3^{\prime \prime} \mathrm{N}, 105^{\circ} 33^{\prime} 31.05^{\prime \prime} \mathrm{E}\right)$ 。点位均选取在耕地的 边缘, 这样既能充分接受灌溉, 也可以忽略植物根系的影 响作用。在三个试验点处挖取 4 米深洞, 分别在不同深度 取原状土样进行烘干试验测定其初始的含水率, 以及颗粒 分析试验测定其土壤中颗粒组成。然后按照当地现行的灌 溉标准, 即每平方米浇灌150方水进行灌溉, 随后的三十 天里, 利用中子水分仪测定不同深度土壤中中子数的数量 并求算其含水率的变化, 与最终的模拟结果进行比照。

\section{Hydrus $-1 D$ 模型建立及参数设置}

\section{1. 土壤水分运动方程}

在非饱和多孔介质中, 水分运移主要为一维的垂向运 动, 因此利用Hydrus-1D软件模拟土壤水的入渗过程时, 采用修正的Richards方程 [10]:

$$
\frac{\partial \theta}{\partial t}=\frac{\partial}{\partial z}\left[K(\theta)\left(\frac{\partial h}{\partial z}+\cos \alpha\right)\right]-S
$$

式中: $\theta$ 是土壤含水率, $\mathrm{cm}^{3} / \mathrm{cm}^{3}$; $\mathrm{t}$ 是时间, $\mathrm{d} ; \mathrm{z}$ 是 土壤深度, $\mathrm{cm}$; $\mathrm{K}$ 是土壤非饱和导水率, $\mathrm{cm} / \mathrm{d} ; \mathrm{h}$ 是土壤负 压水头, $\mathrm{cm} ; \mathrm{a}$ 是水流方向与垂直轴的夹角; $\mathrm{S}$ 是植物根 系吸水, $1 / \mathrm{L}$ 。

由于本次模拟只涉及到水分在垂直方向的运移, 即水 流方向与垂直轴的夹角为 $0^{\circ}$, 且所选试验点位均在耕地 边缘, 可忽略植物根系的影响作用, 因此 $\cos \alpha=1 、 S=0$ 。 于是Richards方程可简写为:

$$
\frac{\partial \theta}{\partial t}=\frac{\partial}{\partial z}\left[K(\theta)\left(\frac{\partial h}{\partial z}+1\right)\right]
$$

\section{2. 土壤水分特征方程}

由于在修改后的Richards 方程里涉及到含水率 $\theta$ 、负 压水头 $\mathrm{h}$ 、非饱和土壤导水率 $\mathrm{K}$ 三个未知函数, 并且负压水 头 $\mathrm{h}$ 与土壤导水率 $\mathrm{K}$ 都是含水率 $\theta$ 的函数, 因此在 Hydrus-1D软件中选择最常用的Van Genuchten-Mualem 模型 $[11]$, 其表达式为: 


$$
\begin{aligned}
& \theta(h)= \begin{cases}\theta_{r}+\frac{\theta_{s}-\theta_{r}}{\left[1+|\alpha h|^{n}\right]^{m}} & h<0 \\
\theta_{s} & h>0\end{cases} \\
& K(h)=K_{s} S_{e}^{l}\left[1-\left(1-S_{e}^{\frac{l}{m}}\right)^{m}\right]^{2}
\end{aligned}
$$

其中 $S_{e}=\frac{\theta-\theta_{r}}{\theta_{s}-\theta_{r}}, m=1-\frac{1}{n}$

式中: $\theta$ 是土壤含水率, $\mathrm{cm}^{3} / \mathrm{cm}^{3} ; \theta_{\mathrm{r}}$ 是土壤残余含 水率, $\mathrm{cm}^{3} / \mathrm{cm}^{3} ; \theta_{\mathrm{s}}$ 是土壤饱和含水率, $\mathrm{cm}^{3} / \mathrm{cm}^{3} ; \mathrm{a}, \mathrm{m}$, $\mathrm{n}$ 是经验参数; $\mathrm{K}_{\mathrm{s}}$ 是土壤饱和导水率, $\mathrm{cm} / \mathrm{d} ; \mathrm{S}_{\mathrm{e}}$ 是有效含水 率; 1 是孔隙连通性参数。

\section{3. 初始条件与边界条件}

初始条件为模拟开始时土壤含水率, 在各试验点分别 取纵向不同深度土层的原状土样, 通过烘干试验测得各点 处初始条件下的含水率值, 即 $\theta(\mathrm{z}, \mathrm{t})=\theta_{0}(\mathrm{z}), \mathrm{t}=0$ 。由于 腰坝绿洲无地表径流, 因此试验点的上部边界与大气直接 接触; 而试验点下部仍处于包气带中, 未达到饱和状态, 故下部边界属于自由入渗。上下边界条件均可在 Hydrus-1D模型中选取 [12]。

\section{4. 土壤特征参数}

在三个试验点分别取各纵向深度土层的原状土样, 通 过颗粒分析实验可得每个土样的粘粒、粉粒、砂粒所占百 分比, 根据美国质土壤质地分类标准可得三个点处土层分 布情况如表1所示:
表1 土壤分层。

\begin{tabular}{llllll}
\hline 号点 & & \multicolumn{2}{l}{ 2号点 } & \multicolumn{3}{l}{ 3号点 } \\
\hline 深度 $(\mathrm{cm})$ & 土壤质地 & 深度 $(\mathrm{cm})$ & 土壤质地 & 深度 $(\mathrm{cm})$ & 土壤质地 \\
\hline $0-30$ & 粉壤土 & $0-180$ & 砂土 & $0-280$ & 粉壤土 \\
$30-50$ & 壤砂土 & $180-230$ & 粉粘土 & $280-330$ & 壤砂土 \\
$50-90$ & 粉壤土 & $230-280$ & 粉壤土 & $330-400$ & 砂土 \\
$90-400$ & 壤砂土 & $280-350$ & 砂壤土 & & \\
& & $350-400$ & 砂土 & & \\
\hline
\end{tabular}

通过Hydrus-1D模型内部自带的神经网络预测功能 [13], 输入土样的粘粒、粉粒、砂粒各自所占百分比, 即 可得到各点处的相关土壤水力参数: 残余含水率 $\theta_{\mathrm{r}}$, $\mathrm{cm}^{3} / \mathrm{cm}^{3}$; 饱和含水率 $\theta_{\mathrm{s}}, \mathrm{cm}^{3} / \mathrm{cm}^{3}$; 经验参数 $\alpha$; 曲线形 状参数 $\mathrm{n}$; 土壤饱和导水率 $\mathrm{K}_{\mathrm{s}}, \mathrm{cm} / \mathrm{d}$; 曲率系数 1 , 具体如 表2所示:

表2 土壤水力参数。

\begin{tabular}{llllllll}
\hline 点号 & \multicolumn{2}{l}{ 土壤质地 $\boldsymbol{\theta}_{\mathbf{r}}$} & $\boldsymbol{\theta}_{\boldsymbol{s}}$ & $\boldsymbol{\alpha}$ & $\mathrm{n}$ & $\mathrm{K}_{\boldsymbol{s}}$ & 1 \\
\hline \multirow{2}{*}{1 号点 } & 粉壤土 & 0.0568 & 0.4186 & 0.0046 & 1.6701 & 25.23 & 0.5 \\
& 壤砂土 & 0.0349 & 0.3913 & 0.0459 & 1.7517 & 113.40 & 0.5 \\
& 砂土 & 0.0471 & 0.3822 & 0.0372 & 3.2592 & 629.33 & 0.5 \\
2 号点 & 粉粘土 & 0.1034 & 0.5116 & 0.0122 & 1.4132 & 11.29 & 0.5 \\
& 粉壤土 & 0.0735 & 0.4742 & 0.0070 & 1.6102 & 13.30 & 0.5 \\
& 砂壤土 & 0.0298 & 0.3979 & 0.0327 & 1.4187 & 66.29 & 0.5 \\
& 粹壤土 & 0.0686 & 0.4454 & 0.0050 & 1.6595 & 17.36 & 0.5 \\
3 号点 & 壤砂土 & 0.0586 & 0.4285 & 0.0043 & 1.6917 & 24.65 & 0.5 \\
& 砂土 & 0.0372 & 0.3886 & 0.0439 & 1.7618 & 112.32 & 0.5 \\
\hline
\end{tabular}

\section{4. 模拟结果与分析}

1 号点处不同深度土壤含水率随时间变化如图2所示:

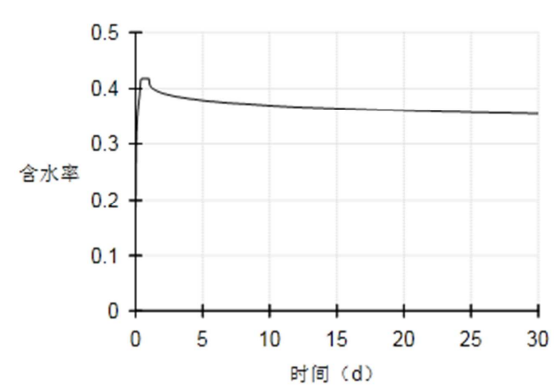

(a) $0 \mathrm{~cm}$ 处

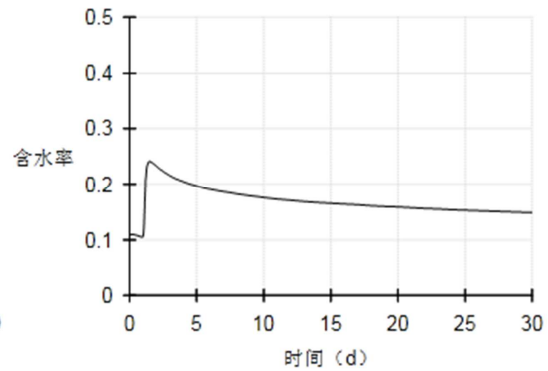

(b) $100 \mathrm{~cm}$ 处

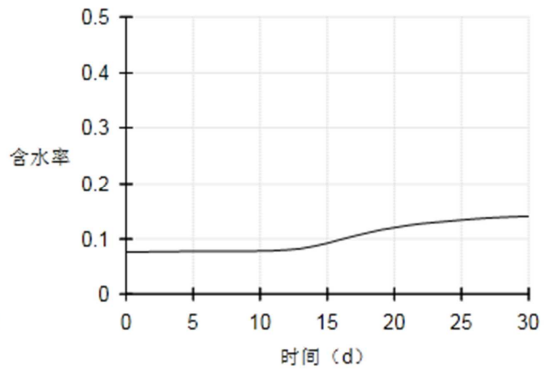

(c) $200 \mathrm{~cm}$ 处

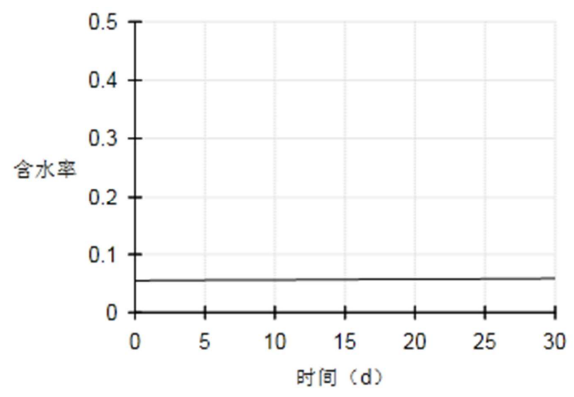

(d) $300 \mathrm{~cm}$ 处

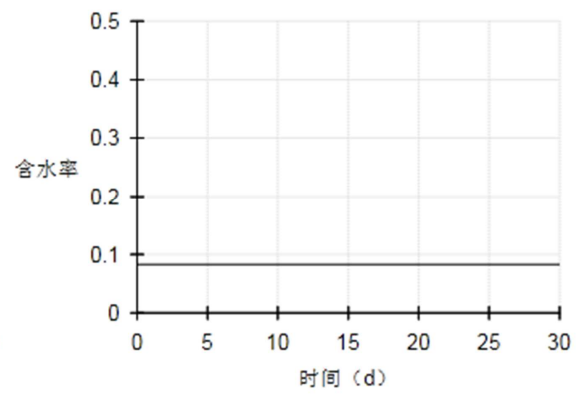

(e) $400 \mathrm{~cm}$ 处

图2 1号点不同深度含水率随时间变化情况。 
由图2可得, 地表的粉壤土在灌溉初含水率即达到饱 和状态, 随后的二十九天里缓缓下降, 但仍然保持较高的 含水率; $100 \mathrm{~cm}$ 处的壤砂土在第二天含水率突然增大, 但 远未达到饱和状态, 随后不断下降, 下降幅度超过粉壤土;

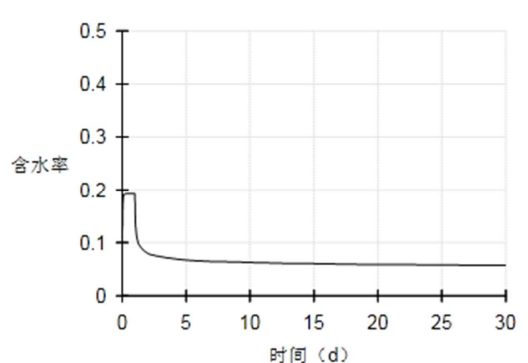

(a) $0 \mathrm{~cm}$ 处

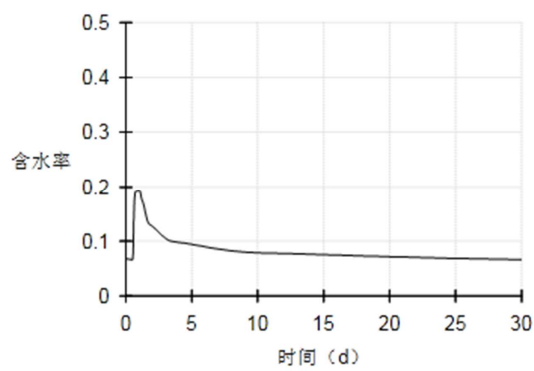

(b) $100 \mathrm{~cm}$ 处
$200 \mathrm{~cm}$ 处的壤砂土的含水率从第十三天起缓慢增大, 最终 稳定值略低于 $100 \mathrm{~cm}$ 处; 而 $300 \mathrm{~cm} 、 400 \mathrm{~cm}$ 处在三十天的模 拟过程中，含水率未发生变化。

2 号点处不同深度土壤含水率随时间变化如图3所示:

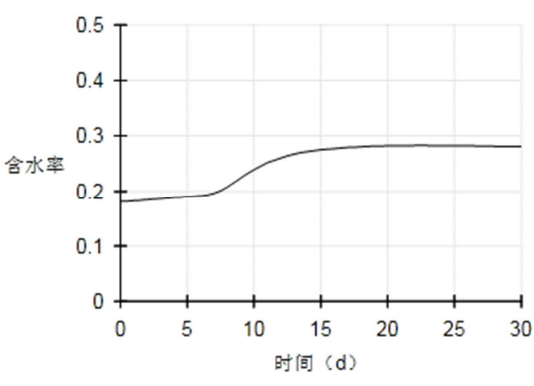

(d) $300 \mathrm{~cm}$ 处

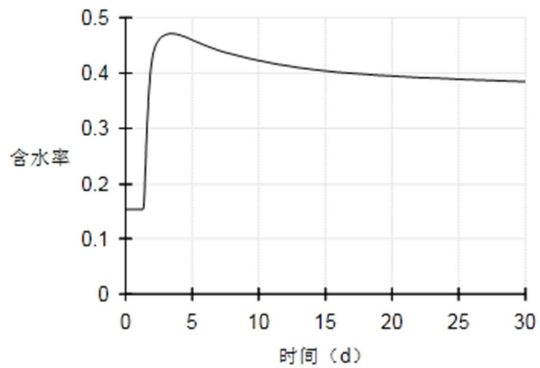

(c) $200 \mathrm{~cm}$ 处

图3 2 号点不同深度含水率随时间变化情况。

由图3可得, 地表与 $100 \mathrm{~cm}$ 处的砂土在灌溉初含水率突 然增大, 但远未达到其饱和含水率, 随后不断下降稳定在 较低值处; $200 \mathrm{~cm}$ 处的粉壤土含水率在第三天开始增大, 几乎达到其饱和含水率值, 随后缓慢下降, 最终稳定在较

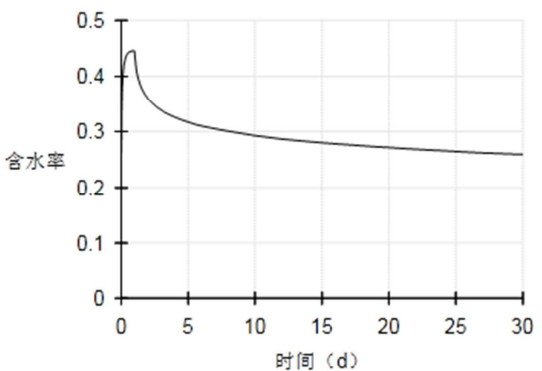

(a) $0 \mathrm{~cm}$ 处

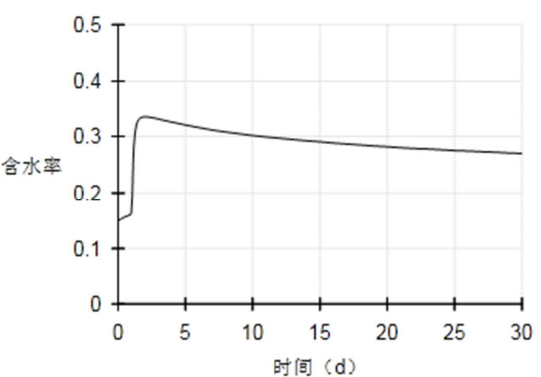

(b) $100 \mathrm{~cm}$ 处

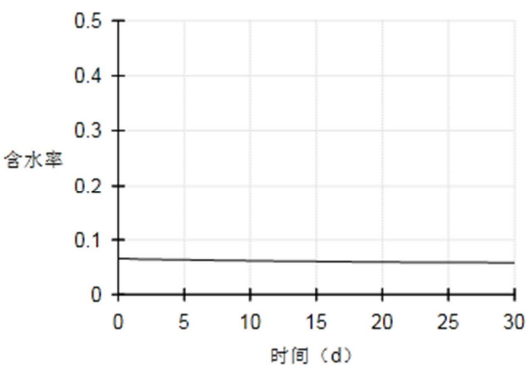

(e) $400 \mathrm{~cm}$ 处
高含水率处; $300 \mathrm{~cm}$ 处砂壤土的含水率从第八天起缓慢增 大, 变化幅度不大; 而 $400 \mathrm{~cm}$ 处在三十天的模拟过程中, 含水率未发生变化。

3 号点处不同深度土壤含水率随时间变化如图4所示:

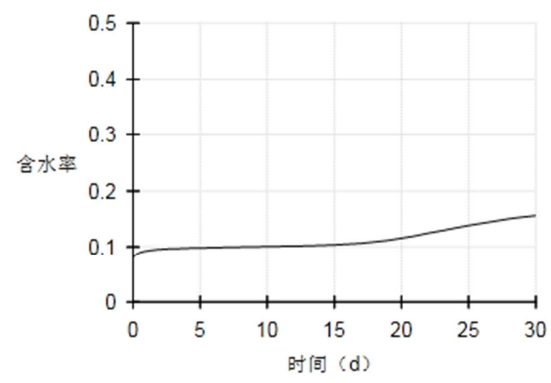

(d) $300 \mathrm{~cm}$ 处

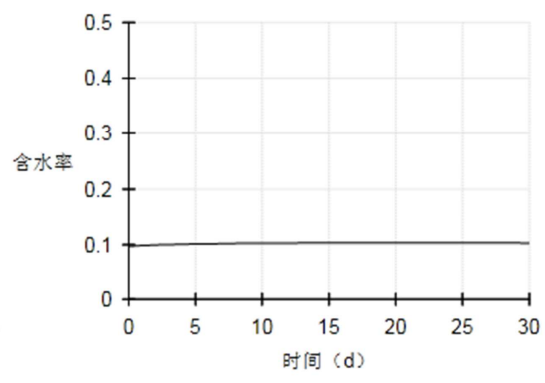

(e) $400 \mathrm{~cm}$ 处

图4 3号点不同深度含水率随时间变化情况。 
由图4可得, 地表与 $100 \mathrm{~cm}$ 处的粉壤土在灌溉初含水率 即突然增大, 其中地表处含水率达到饱和状态, 随后均缓 缓下降, 但仍然保持较高的含水率; $200 \mathrm{~cm}$ 处粉壤土的含 水率在第四天开始增大, 最终与其上方的粉壤土基本维持 在同一值处; $300 \mathrm{~cm}$ 处砂壤土的含水率在第十七天开始缓 慢增大, 最终保持在较低值处; 而 $400 \mathrm{~cm}$ 处在三十天的模 拟过程中, 含水率未发生变化。

\section{5. 结论}

本文利用Hydrus-1D软件对腰坝绿洲灌溉入渗过程进 行模拟, 主要得到以下几个结论:

(1) 本次模拟所得结果与利用中子水分仪实际测量 所得结果较为拟合, 表明Hydrus-1D模型具有较高的仿真 度, 因此模拟的结果可为腰坝绿洲制定更加合理的灌溉制 度提供科学依据;

（2）灌溉水对地下水的补给有限。三个点的入渗极 限在 30 天内都未到达 $400 \mathrm{~cm}$, 由当地的资料得, 即使是在 地下潜水位埋深最浅的三号点处, 埋深也超过了十米, 故 而可以推断在腰坝绿洲灌溉水对地下水的补给有限;

（3）壤土是比较理想的农业土壤。从模拟结果可以 看出壤土含水量一直保持在较高值处, 远远高于砂土, 并 且水分在壤土中入渗速率较快。腰坝绿洲主要种植的作物 玉米为耗水作物, 因此壤土是当地比较适宜的农业土壤。

\section{参考文献}

[1] 赵希宁, 吴发启. 土壤水分入渗的研究进展和评述 [J]. 西北 林学院学报, 2004, 19(1) : 42-45。

[2] 赵彬, 周景春, 张存岭等. 降水与土壤含水量关系分析 $[\mathrm{J}]$. 农业灾害研究, 2013, 36 (7) : 14-17。
[3] 市建民, 李育松, 胡昱欣等. 基于HYDRUS-1D模型的大安灌区 旱田灌溉入渗补给研究 $[\mathrm{J}]$. 干旱地区农业研 究, 2014, 32 (2) : 191-195。

[4] 余根尖, 黄介生, 高占义等. 基于HYDRUS 模型不同灌水模式 下土壤水盐运移模拟 [J]. 水利学报, 2013, 44(7)：826-834。

[5] 马欢, 杨大文, 雷慧闽等. Hydrus-1D模型在田间水循环规律 分析中的应用及改进 [J]. 农业工程学报, 2011, 27 (3) :6-12。

[6] 王水献, 周金龙, 余芳等. 应用HYDRUS-1D模型评价土壤水资 源量 [J]. 水土保持研究, 2005, 12 (2) : 36-38。

[7] 李燕, 卢玉东, 李鸿娟等. 腰坝绿洲地下水位动态特征及对 植被变化影响 [J]. 地下水, 2012, 34(4):74-76。

[8］姜凌, 李佩成, 郭建青. 贺兰山西麓典型干旱区绿洲地下水 水化学特征与演变规律 $[\mathrm{J}]$. 地球科学与环境学 报, 2009, 31 (3) :285-290。

[9] 齐月姿, 多亚军, 韩勇等. 阿拉善干旱区缺水解决问题的思 考 $[J]$. 内蒙古水利, 2014, 15(6) : 36-37。

[10] Simunek J, VanGenuchten MT, Sejna M . Development and applications of the HYDRUS and STANMOD software packages and related codes[J]. Vadose Zone Journal, 2008, 7 (2) :587-600.

[11] Van Genuchten MT. A closed - form equation for predicting the hydraulic conductivity unsaturated soils[J]. Soil Science Society of America Journal, 1980, 44 (5) : 892-898.

[12] 毕经伟, 张佳宝, 陈效民等. 应用HYDRUS-1D 模型模拟农田 土壤水渗漏及硝态氮淋失特征 [J]. 农村生态环境, 2004, 20 (2) : 28-32。

[13] 李远, 郑旭荣, 王振华等. 基于Hydrus-1D的土壤水盐运移数 值模拟 [J]. 中国农学通报, 2014, 30 (35) : 172-177。 